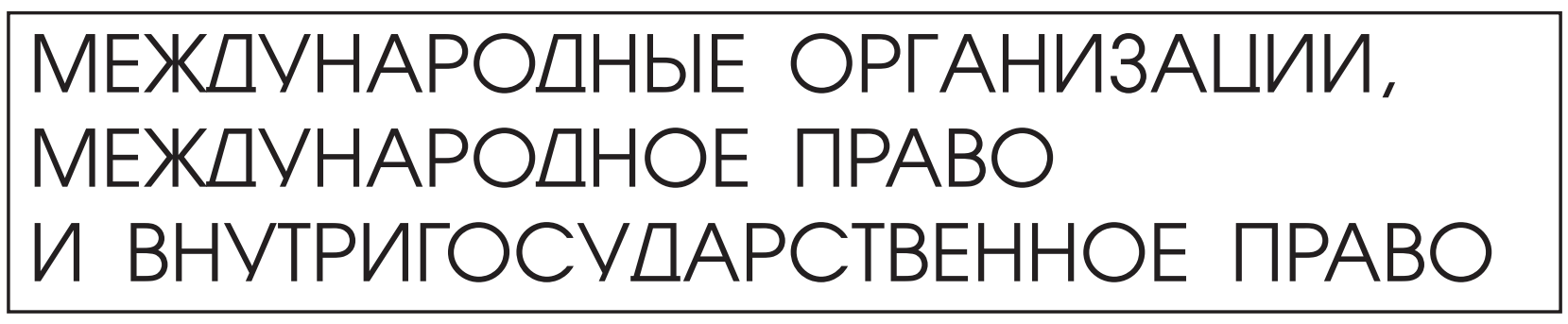

Извеков С.C

\title{
ЭКСТЕРРИТОРИАЛЬНЫЕ НАЛОГОВЫЕ АСПЕКТЫ В ДЕЛАХ О БАНКРОТСТВЕ В СТРАНАХ БРИКС
}

Аннотация. Настоящая статья освещает перспективы постановки налоговых вопросов в трансграничных делах о банкротстве на примере стран БРИКС. Мы сформулируем основные противоречия в соотношении очередности налоговых требований в государственном праве стан БРИКС, оченим ситуацию непосредственного участия государства в деле о банкротстве в другом государстве и наметим пути преодоления сопутствующих этому проблем. В статье продолжена работа автора по определению теоретических основ влияния и взаимодействия фискальных требований государства с подобными фискальными интересами другого государства. Рассмотрены подходы стран БРИКС к категории публичные требования и соотношение с понятием обязательный платеж. В основе работы использован сравнительный метод, путем соотношения примеров трансграничных банкротств, национального законодательства о банкротстве принятого в странах БРИКС. Автором подтверждень расхождения начионального законодательства об очередности удовлетворения требований кредиторов в некоторых странах БРИКС. В обоснование идеи исследования выбранной тематики в рамках содружества БРИКС предложены аргументы. Кроме того, выявлены предпосылки для участия уполномоченных органов одних стран в производствах, возбужденных на территории других стран БРИКС. Видится, что представленныйматериал может быть интересен для исследователей международного частного права, международного налогового права, а также вопросов трансграничного банкротства. Ключевые слова: Трансграничное банкротство, трансграничная несостоятельность, lex fori concursus, налоговые вопросы, обязательный платеж, конкуренция иностранных требований, конфликт иностранных требований, равенство прав, санация, принцип взаимности. Abstract: This article elucidates the prospects for posing tax questions in the transboundary bankruptcy cases on the examples of the BRICS countries. We will formulate the main collisions in comparison of the sequence of tax requirements in state law of the BRICS countries, assess the situation of direct involvement of the state in bankruptcy cases in another country, and establish paths for overcoming the issues arising in the process. The author defines the theoretical foundations of the influence and cooperation of the fiscal demands of a state with similar fiscal interests of another state. The author explores approaches of the BRICS countries towards the category of public demands and correlation with the concept of mandatory payment. The article substantiates the disagreements of national legislation on priority of satisfaction of demands of the creditors in some of the BRICS countries. The presented material can be useful for researchers of international private law and international tax law in dealing with cases of transboundary bankruptcy. 
Keywords: Transboundary bankruptcy, Transboundary failure, Tax questions, Lex fori concursus, Obligatory payment, Competitiveness of foreign requirements, Conflict of foreign requirements, Equality of rights, Financial rehabilitation, Principle mutuality.

анкротство для организации является инструментом укрепления экономической стабильности в обществе на основании законных способов освобождения от безнадежных долгов (fresh start). Это не просто ликвидация организации с непогашенными долгами. Полагаем исследуемые вопросы не должны восприниматься в негативном свете. Наоборот, мы предлагаем разработать ясные и эффективные механизмы надежной защиты интересов частных и публичных кредиторов, путем перераспределения активов в соответствии с потребностями рынка. Крупная экономическая деятельность, даже международного масштаба, не застрахована от неудачи и банкротства.

В настоящее время, термин «Трансграничная несостоятельность» («Cross-Border Insolvency») имеет официальное закрепление в резолюции Генеральной Ассамблеи $\mathrm{OOH}$ (типовой закон о трансграничной несостоятельности ЮНСИТРАЛ 1997 г.[1].

Государства БРИКС вовлечены в процессы глобальных банкротств, однако, общепризнанно Россия не участвует в таких отношениях ввиду отсутствия достаточного нормативного регулирования. Анализируя законодательство России можно констатировать отсутствие системного регулирования в этой сфере. В Федеральном законе от 26.10.2002 г. № 127-Ф3 «О несостоятельности (банкротстве)» [2] (далее - Закон о банкротстве) упоминается термин «трансграничная несостоятельность». В целом провозглашен принцип равенства иностранных и отечественных кредиторов в производстве по делам о несостоятельности (п. 5 ст. 1 Закона о банкротстве). Как и в любой другом законе закреплен приоритет международных договоров над национальным правом. Кроме того, руководствуясь принципом взаимности в делах о банкротстве на территории Российской Федерации признаются решения иностранных судов.

Приведенное регулирование нельзя признать исчерпывающим и достаточным, так ка толкование понятия трансграничная несостоятельность возможно только в одном направлении: привязка к иностранному государству через кредиторов должника либо его имущество. Неурегулированной остается противоположный аспект, когда должником является иностранная компания [3].

Непосредственно Гражданский кодекс Российской Федерации не регулирует вопросы трансграничной несостоятельности. В этой связи ученые [4 - 13] открыто осуждают отсутствие специального нормативного правового акта посвящённого несостоятельности, осложнённой иностранным элементом.

Международный опыт регулирования банкротств, в которых должник и кредиторы принадлежат к разным государствам либо активы должника рассредоточены на территориях двух и более государств, уже давно стало предметом научных дискуссий и нормативного регулирования за рубежом [14 - 17].

История дает множество примеров для совершенствования как национального права, так и способов международного урегулирования спорных вопросов в делах о несостоятельности, осложнённых иностранным элементом:

Bo-nервых, это многосторонние международные соглашения:

Европейская конвенция о трансграничной несостоятельности 1960 г., предлагавшая открывать производство только в одной из 
договаривающихся стран. Данная конвенция в настоящий момент не применяется, но представляет доктринальный интерес.

Европейская конвенция о некоторых международных аспектах банкротства 1990 г. Конвенция подписана и применяется при проведении параллельных производств в договаривающихся странах.

Конвенция Европейского союза о трансграничной несостоятельности 1995 г. ориентирует станы участницы на ликвидационный уклон и оперирует сочетанием приемов выше обозначенных конвенций.

Типовой закон «О трансграничной несостоятельности» ЮНСИТРАЛ 1997 г. Данные международный акт рекомендует принятие национального закона, который регулирует вопросы информационного обмена и преимущественно применим к производствам, открытым в одной стране.

Регламент Европейского парламента о процедурах несостоятельности 2000 г. Названный регламент предусматривает возбуждение главной процедуры по месту нахождения центра интересов должника и возможность существования второстепенных процедур в договаривающихся странах.

При этом относимыми к теме настоящего исследования являются только рекомендации типового закона ЮНСИТРАЛ 1997 г., поскольку участники БРИКС являются членами Организации объединенных наций.

Непосредственно для участников БРИКС опыт коллизионного регулирования может быть пополнен из иных международных соглашений, например, нормы кодекса Бустаманте (IX Глава), нормы Унифицированного акта ОХАДА «Об организации коллективных процедур ликвидации» [18], а также договоров Монтевидео $[19,20]$, заключенных на первом южно-американском конгрессе по международному частному праву в Монтевидео 12.03.1889 г. и втором южно-американском конгрессе по международному частному праву проходившем с 1939 по 1940 гг. в Монтевидео.

Bo-вторых, двусторонние договоры по вопросам банкротства:

Договор между Францией и Швейцарской Республикой от 19.08.1798 г. (дополненный договорами от 28.05.1799 г. и 27.09.1803 г.);

Конвенция между Швейцарскими кантонами и Вюртембергом от 13.05.1826;

Договор между Францией и Швейцарией от 15.06.1869 г.;

Конвенция между Бельгией и Францией «О юрисдикции, действительности и приведении в исполнение судебных и арбитражных решений, а также аутентичных правовых актов» (Париж, 08.07.1899 г.);

Конвенция между Бельгией и Австрией «О банкротстве, ликвидации, мировых соглашениях и приостановлении платежей» (Брюссель, 16.07.1969 г.) с дополнительным протоколом от 13.06.1973 г.;

Конвенция между Бельгией и Нидерландами «О территориальной юрисдикции, банкротстве и приведении в исполнение судебных и арбитражных решений, а также аутентичных правовых актов»с дополнительным протоколом (Брюссель, 28.03.1925 г.);

Договор между Германией и Австрией «О банкротстве, ликвидации, урегулировании и мировых соглашениях» (Вена, 25.05.1979 г.);

Конвенция между Францией и Австрией «О юрисдикции, признании и приведении в исполнение решений в делах о банкротстве» (Вена, 27.02.1979 г.);

Конвенция между Францией и Италией «О приведении в исполнение решений по гражданским и коммерческим делам» (03.06.1930 г.);

Конвенция между Италией и Австрией «О банкротстве, ликвидации и мировых соглашениях» (Рим, 12.07.1977 г.);

Конвенция между Королевством Нидерландов и Федеративной Республикой 
Германия «О взаимном признании и приведении в исполнение решений и актов по гражданским и коммерческим делам» (Гаага, 30.08.1962 г.);

Конвенция между Соединенным Королевством и Королевством Бельгия, предусматривающая взаимное признание и приведение в исполнение решений по гражданским и коммерческим делам, с протоколом к ней (Брюссель, 02.05.1934 г.).

Указанные двусторонние соглашения по вопросам банкротства склонялись к принципу универсализма и закрепляли принцип взаимного признания иностранных судебных решений, юрисдикции домицилия или места основного ведения бизнеса, а также полномочий управляющих, назначенных в делах о банкротстве, если это не противоречило соображениям публичного порядка [13, с. 180-200].

Двусторонняя модель не является универсальной и позволяет решать вопросы исключительно на территории двух стран, что в полной мере не исключает проблемы при увеличении сферы трансграничного банкротства на территории трех и более стран, даже при наличии между ними двусторонних соглашений. В этой связи тенденциозно решение о замене поименованных выше двусторонних актов положениями Регламента ЕС № 1346/2000. Согласно статьи 44 Регламента ЕС № 1346/2000 названные выше соглашения были заменены Регламентом.

Актуальность проблемы для участников БРИКС бесспорна: банкротства с экстерриториальным эффектом не обошли стороной участников объединения. Для Китая тема банкротства частных предприятий является относительно молодой, поскольку применяется с 2007 года. Ранее вопрос о государственных требованиях вообще не поднимался, так как ранее действовавший закон затрагивал только государственные предприятия и целью процедуры было максимальное погашение требований работников. В апреле 2015 года Компания Baoding Tianwei, дочернее подразделение China South Industries Group, сообщила о дефолте и неспособности погасить в срок собственные облигации на сумму 13,8 млн. долл. [21]. Другой крупный девелопер Kaisa Group также объявил о дефолте [22]. Небезызвестная бразильская нефтяная компания OGX, в 2013 подала заявление о банкротстве [23]. OGX имела долг в 5,11 млрд. долл. Ее банкротство было крупнейшим в корпоративной истории стран Латинской Америки. В конце 2014 около 30 бразильских компаний производителей сахара и этанола подали на банкротство.

Россия, в свою очередь, сталкивается с вопросами банкротства преимущественно в тех случаях, когда обособленные споры не могут быть рассмотрены в рамках иностранных производств и имеют отношение к российским компаниям, примерами тому являются Постановление Президиума ВАС РФ № 10508/13 от 12.11.2013, Постановление Президиума ВАС от 04.10.2011 № 6417/11, Определение ВАС РФ № 11934/04 от 23.06.2008, Определение ВАС РФ № 14334/07 от 11.03.2008, Определение ВАС РФ № ВАС-6393/09 от 17.07.2009, Постановление ФАС Волго-Вятского округа по делу № А793955/2009 от 11.03.2011.

Рассмотренные ситуации являются единичными случаями обширной международной практики рассмотрения споров о несостоятельности в трансграничном аспекте.

Важным достижением юридической техники и нормативного регулирования для стран-участниц БРИКС может стать закрепление как в национальном законодательстве, так и в международных соглашениях коллизионный нормы о применимости праве к делам о банкротстве с иностранным элементом, например, что применимое право 
следует праву государства места возбуждения производства (lex fori concursus).

Формат БРИКС может стать тем самым «fresh start» развития нормативной основы трансграничной несостоятельности и ее пресечения.

Рассматриваемая ситуация недостаточного регулирования вопросов трансграничной несостоятельности для стран участниц БРИКС действительно может быть легко восполнена благодаря практическим примерам, представленным в международной практике.

Одновременно с этим невозможно решить вопрос об учете требований иностранного государства по налогам и сборам путем простого заимствования, так как ни одно существующее соглашение не регулирует такие вопросы. Сотрудничество стран БРИКС открывает магистрали новой экономической деятельности и международного банковского дела, и может стать основой для качественного развития юридической мысли об учете публичного интереса договаривающегося государства в делах о банкротстве.

Рассмотрим основные налоговые вопросы в рамках дел о банкротстве, осложненных иностранным элементом.

1. Формирование единых критериев для взаимного признания публичных требований договаривающихя государств. Во-первых, можно непосредственно закрепить необходимые критерии в международном договоре. Во-вторых, допускаем одностороннее признание одним государством публичных требований иного государства на уровне национального права. Примером тому является статья 5 закона о банкротстве [24] в Китайской Народной Республике, согласно которой, в случае, если суд иностранного государства принял имеющее законную силу решение или определение в отношении дела о банкротстве, причем данное решение (определение) касается имущества должника на территории КНР и содержит просьбу или требование к народному суду о признании и исполнении решения (определения), народный суд в соответствии с положениями международных конвенций, участником или подписантом которых является КНР, либо в соответствии с принципом взаимности проводит проверку и выносит определение о признании и выполнении данного документа, если считает, что его выполнение не нарушает основных принципов законодательства, государственной безопасности, суверенитета, общественных интересов КНР, а также законных прав и интересов кредиторов на территории КНР. Однако приведенная норма не устанавливает единых критериев публичных требований, а в общих чертах признает их существование и возможное значение для договаривающегося государства.

2. Приведение к единому знаменателю категорий публичное требование и обязательный платеж. Официальное позитивное понятие обязательного платежа в деле о банкротстве содержится в статье 2 Федерального закона от 26.10.2002 № 127Ф3 «О несостоятельности (банкротстве)». Обязательные платежи - налоги, сборы и иные обязательные взносы, уплачиваемые в бюджет соответствующего уровня бюджетной системы Российской Федерации и (или) государственные внебюджетные фонды в порядке и на условиях, которые определяются законодательством Российской Федерации, в том числе штрафы, пени и иные санкции за неисполнение или ненадлежащее исполнение обязанности по уплате налогов, сборов и иных обязательных взносов в бюджет соответствующего уровня бюджетной системы Российской Федерации и (или) государственные внебюджетные фонды, а также административные штрафы и установленные уголовным законодательством штрафы. Указанное выше понятие нельзя 
признать исчерпывающим и раскрывающим все виды обязательных платежей.

Высшим Арбитражным судом РФ в Постановлении Пленума ВАС РФ от 23.07.2009 № 59 «О некоторых вопросах практики применения Федерального закона «Об исполнительном производстве»в случае возбуждения дела о банкротстве», дано расширенное толкование, по которому исполнительский сбор также относится к обязательным платежам. Там же в пункте 17 указан специальный порядок удовлетворения требований, в основе которых исполнительский сбор (пункт 3 статьи 137 Закона о банкротстве).

Не безызвестны правовые позиции, сформулированные Конституционным Судом Российской Федерации в Определении от 10 декабря 2002 г. № 284-О «По запросу Правительства Российской Федерации о проверке конституционности Постановления Правительства Российской Федерации «Об утверждении порядка определения платы и ее предельных размеров за загрязнение окружающей природной среды, размещение отходов, другие виды вредного воздействия» и статьи 7 Федерального закона «О введении в действие части первой Налогового кодекса Российской Федерации», согласно которым платежи за негативное воздействие на окружающую среду являются обязательными публично-правовыми платежами (в рамках финансово-правовых отношений). Они носят индивидуально-возмездный и компенсационный характер и являются по своей правовой природе фискальным сбором. С учетом изложенной позиции Конституционного Суда Российской Федерации, рассматриваемые платежи за негативное воздействие на окружающую среду также входят в понятие обязательный платеж, приведенное в статье 2 Закона о банкротстве.

Законом о банкротстве прямо не называются обязательные платежи - тамо- женные пошлины - обязательный платеж, взимаемый таможенными органами в связи с перемещением товаров через таможенную границу (см., Таможенный кодекс Таможенного союза).

Законодательство о банкротстве иных стран БРИКС не выделяет категорию «обязательные платежи» в том или ином значении, а по своей сути является бланкетным, отсылающим к отраслевым актам о налогах, сборах и прочих обязательных публичных платежах. Следовательно, коллизии в толковании и установлении публичных требований не исключены.

\section{3. Предоставление уполномоченным} органам иностранного государства равных прав по сравнению с собственным компетентным государственным органом, либо признание иностранного государственного органа уполномоченным представителем государства-кредитора. Проблема может быть разрешена путем признания компетентного органа иностранного государства равноправным кредитором. Представляется не вполне обоснованным наделение соответствующего органа равнозначной компетенцией сравнимой с национальным уполномоченным органом, так как права этого органа формируются не столько в рамках законодательства о банкротстве, сколько в рамках административно-правового регулирования. Статус уполномоченного органа является следствием компетенции, а не наличием непосредственной финансовой взаимосвязи с должником. Проблематичным остается ситуация необоснованного вторжения в суверенные права иностранного государства при уравнивании прав иностранного органа и российских налоговых органов.

4. Устранение коллизий в различной очередности удовлетворения требований по налоговым обязательствам. Для примера сравним установленную очередность 
требований по законодательству Китая, Бразилии и России.

Статья 113 Закона о банкротстве Китая предусматривает, что после приоритетного погашения расходов на банкротство и общих обязательств имущество банкротства направляется на погашение обязательств в следующей очередности:

1. задолженность по выплате заработной платы, медицинским пособиям, компенсациям нетрудоспособности или инвалидности, пособиям по утрате кормильца, базовому пенсионному и медицинскому страхованию трудового коллектива, а также иным компенсациям, которые должник обязан выплачивать работникам в соответствии с положениями законодательства и подзаконных актов;

2. задолженность по социальному страхованию по иным статьям, за исключением указанных в предыдущем подпункте, а также налоговые платежи, по которым должник имеет задолженность;

3. обычные права кредитора.

В Законе о банкротстве Бразилии установлена следующая очередность требований кредиторов:

1. задолженность по выплате заработной платы и связанные с ней платежи;

2. задолженность перед кредиторами, права которых обеспечены залогом;

3. задолженность по налогам и сборам;

4. задолженность перед иными кредиторами [25].

В России налоговые обязательства учитываются в составе третьей очереди наравне с иными кредиторами (статья 134 Закона о банкротстве), что иной раз критикуют [26, 27].

Представляется справедливым с учетом принципа взаимности относить требования иностранного государства к той очереди к которой относятся собственные требования.
Однако на практике это может привести к ухищрениям отдельных частных кредиторов, направленных на вывод производства в более благоприятную юрисдикцию - «банкротный туризм» [28 - 29]. Предложение урегулировать эту коллизию в международном договоре приведет к ущемлению прав кредиторов самим фактом участия иностранного государства в деле о банкротстве. Поэтому взаимность и уважение к суверенному «мнению» относительно национальной очередности требований каждого договаривающегося государства является ориентиром и естественным риском договаривающейся стороны.

Отдельного рассмотрения заслуживает вопрос об очередности публичных требований при множественности производств: параллельные или подчиненные производства.

5. Санация должника, финансовое оздоровление и мировое соглашение по делам о банкротстве, осложненными фискальными требованиями иностранного государства в содружестве БРИКС.

Вопрос оздоровления (реабилитации) вместо ликвидации должен господствовать в делах о банкротстве, но разрозненное национальное законодательство о банкротстве стан БРИКС может не просто осложнить оздоровление компании, но и заблокировать эту возможность.

Например, в Федеративной Республике Бразилии и Южно-Африканской республике применяется неизвестный и возможно противоречащий российскому и китайскому праву неттинг. Под неттингом понимают метод определения размера обязательств путем агрегирования, комбинирования, взаимозачета двух или более обязательств.

Данная конструкция отчасти чужда России и КНР, где предусмотрена оспоримость таких соглашений. При этом отсутствие пределов мирового соглашения в российском праве может быть использова- 
но для законного «прикрытия» неттинга. Одновременно с этим, Закон о банкротстве КНР содержит самостоятельные мероприятия о зачете, замене кредитора примирении и финансовом оздоровлении.

В этой связи гармонизация национального законодательства о банкротстве необходима одновременно с решением коллизионных вопросов на уровне международных соглашений.

6. Отсутствие условий реализации принципов взаимности и добросовестности профессиональных управляющих, судов, органов, представляющих интересы казны. Взаимность договаривающихся стран проявляется через взаимность и добросовестность непосредственных участников дел о трансграничной несостоятельности. Безусловно регламент взаимодействия всех задействованных лиц требует единой кодификации, например, путем заключения многостороннего международного договора стран БРИКС или принятия рекомендации ЮНСИТРАЛ для дальнейшего национального закрепления. В частности, ЮАР с 2000 года внедрило в национальное законодательство рекомендации ЮНСИТРАЛ; в России подготовлены два законопроекта об имплементации норм ЮНСИТРАЛ, но ни в 2009 году [29], ни в 2011 году [30], ни позднее законопроекты не были приняты в окончательном виде.

В отношении Китая и Бразилии отсутствует достоверная информация о работе над внедрением рекомендаций ЮНСИТРАЛ в национальное законодательство.

Индия активно работает над законом о трансграничной несостоятельности и опирается в этой деятельности не только на указанные выше рекомендации ЮНСИТРАЛ, но и на Меморандум Совета Международной ассоциации юристов 2005 г. и на проект закона о транснациональной несостоятельности, разработанный Американским институтом права НАФТА [31].

Отдельного внимания заслуживает гармонизация норм о банкротстве муниципалитета договаривающегося государства, которые применяется в ЮАР и Бразилии.

Можно заключить, что формат международного сотрудничества БРИКС пока свободен в сформированной собственной модели в вопросах трансграничной несостоятельности и может стать положительным примером другим государствам и международным организациям для эффективного разрешения соответствующих вопросов с учетом публичных интересов государств-кредиторов. Новая для международного права структура создана для повышения эффективности экономики каждого своего члена, и четкое закрепление правил санации, финансового оздоровления, освобождения от безнадежных долгов, по нашему мнению, будет иметь не только практический характер, но и превентивный эффект, рассчитанный на укрепление экономических связей участников БРИКС.

\section{Библиография:}

1. Доклад Комиссии ООН по праву международной торговли о работе ее тридцатой сессии 12-30 мая 1997 г. // Генеральная Ассамблея. Официальные отчеты. Пятьдесят вторая сессия. Нью-Йорк, 1997. C. 71-81. (URL: www.uncitral.org);

2. Федеральный закон от 26.10.2002 № 127-Ф3 «О несостоятельности (банкротстве)» // Собрание законодательства РФ, 28.10.2002, № 43, ст. 4190;

3. Мохова Е.В. Доктрина основного производства трансграничной несостоятельности юридических лиц: Дис. ... канд. юрид. наук. М., 2009. С. 27;

4. Мохова Е.В. Трансграничное банкротство: российские правовые реалии и перспективы // Закон. 2014. № 6. C. 62-73; 
5. Мохова Е.В. Оспаривание в российском суде сделок банкротящегося за рубежом должника. Комментарий к Постановлению Президиума ВАС РФ от 12.11.2013 № 10508/13 по делу банка СНОРАС // Вестник ВАС РФ. 2014. № 5. С. 48 - 66;

6. Мохова Е.В. Потребности и перспективы регулирования трансграничной несостоятельности в Российской Федерации // Российское правосудие. 2013. №4;

7. Мохова Е.В. Центр основных интересов должника при трансграничной несостоятельности: перспективы введения в России новых правовых конструкций // Закон. 2012. № 10. С. 111 - 127;

8. Мохова Е.В. Доктрина модифицированного универсализма как основа регулирования трансграничной несостоятельности: разграничение компетенции судов различных государств. М., 2009. С. 10-54;

9. Ануфриева Л.П. Международное частное право: В 3 т. Т. 3: Трансграничные банкротства. Международный коммерческий арбитраж. Международный гражданский процесс. М., 2001. С. 8;

10. Ерпылева Н.Ю. Международное частное право: Учебник. М., 2004. С. 126;

11. Летин А.В. Трансграничная несостоятельность как объект науки МЧП // Государство и право. 2003. № 8. C. $80-81$;

12. Трушников С.С. Возбуждение производства по делам о несостоятельности в России и Германии. СПб., 2006. С. 155;

13. Собина Л.Ю. Признание иностранных банкротств в международном частном праве. М.: Статут, 2012. С 195-205;

14. Мьючурелли Ф. М. Свобода перевоплощения в сфере корпоративного права США и ЕС // научный доклад в Нью-Йоркском университете права и экономики № 11-07.2011, Март 11. URL-aдpec: http:// ssrn.com/abstract=1783607 (дата обращения: 24.11.2015);

15. Гернер-Бойолё С., Шилиг М. Тайны свободы учреждения после Cartesio // Международное и Сравнительное право. 2010. Вып. 59. № 2. URL: http://ssrn.com/abstract=1340964 (дата обращения: 24.11.2015);

16. Вимерш Е. Передача компании Seat в Европейском корпоративном праве // ECGI-Law Working Paper № 08/2003. URL-адрес: http://ssrn.com/abstract=384802 (дата обращения: 24.11.2015);

17. Мьючурелли Ф. М. О неизбежном сохранением поиска удобного суда в Европейском законодательстве о несостоятельности. С. 6 - 7. URL: http://ssrn.com/abstract=2375654 (дата обращения: 24.11.2015);

18. Унифицированный акт Организации по гармонизации коммерческого права стран Африки «Об организации коллективных процедур ликвидации» 1998 г.;

19. Договор о международном коммерческом праве (1889 г.), Договор по вопросам международного коммерческого права (1940 г.), Договор о международном процессуальном праве (1940 г.);

20. Гаванская конвенция по вопросам международного частного права, принятая 20 февраля 1928 г. на Шестой панамериканской конференции, проходившей в г. Гаване (о. Куба);

21. Информационное периодическое издание, 2015. URL: http://www.bloomberg.com/news/articles/2015-04-21/ china-sees-first-bond-default-by-state-firm-with-baoding-tianwei (дата обращения 24.11.2015);

22. Информационное периодическое издание, 2015. URL: http://www.bloomberg.com/news/articles/2015-04-20/ kaisa-defaults-after-china-developer-says-can-t-pay-dollar-debts (дата обращения 24.11.2015);

23. Информационное периодическое издание, 2013. URL: http://www.vedomosti.ru/business/articles/2013/10/31/ brazilskaya-neftyanaya-kompaniya-ogx-obyavila-o-bankrotstve (дата обращения 24.11.2015);

24. Закон Китайской Народной Республики о банкротстве предприятий, принят на 23-м заседании Постоянного комитета Всекитайского собрания народных представителей 10-го созыва 27 августа 2006 г. // (КНР) Бюллетень Постоянного комитета ВСНП за 2006 год; URL: http://www.china.org.cn/ china/2011-02/11/content_21898381.htm (дата обращения 24.11.2015);

25. Араужо А. П., и соавт., Опыт применения Бразильского закона о банкротстве, Дж. корп. Финансы (2012), doi:10.1016/j.jcorpfin.2012.03.001. URL: http://static1.squarespace.com/static/553c6154e4b0ed6ca351a744/t/5 5561788e4b0342593f78d66/1431705480639/pesquisa+03.pdf (дата обращения 24.11.2015);

26. Ласкина С. О. Защита законных финансовых интересов государства при банкротстве юридических лиц: автореф. дис. ... канд. юрид. наук. М., 2010. С. 22;

27. Ласкина С. О. Налоговые обязательства в деле о банкротстве // Хозяйство и право. 2009 № 12. C. $63-78$; 
28. Уолтерс А., Смит А. «Банкротный туризм» по постановлению ЕС о процедурах несостоятельности: взгляд из Англии и Уэльса // Комментарий к международной несостоятельности. 2009. Вып. 19. № 3. П. 181-208; URL: https://www.ntu.ac.uk/PSS/Nottingham\%20Law\%20School/Publications/99914. pdf. (дата обращения 24.11.2015);

29. Проект Федерального закона № 615865-5 «О внесении изменений в Федеральный закон «О несостоятельности (банкротстве) кредитных организаций» и иные законодательные акты Российской Федерации в части совершенствования процедур банкротства кредитных и иных финансовых организаций, усиления ответственности за совершение неправомерных действий в преддверии банкротства» (ред., принятая ГД ФС РФ в І чтении 10.02.2012);

30. Проект Федерального закона «О трансграничной несостоятельности (банкротстве»). URL: http:// economy.gov.ru/minec/activity/sections/ corpmanagment/bankruptcy/doc20110225_04 (дата обращения 24.11.2015);

31. Промежуточный отчет Комитета по реформе конкурсного законодательства, январь 2015. URL: http:// finmin.nic.in/reports/Interim_Report_BLRC.pdf. (дата обращения 24.11.2015).

\section{References (transliterated):}

1. Mokhova E.V. Doktrina osnovnogo proizvodstva transgranichnoi nesostoyatel'nosti yuridicheskikh lits: Dis. ... kand. yurid. nauk. M., 2009. S. 27;

2. Mokhova E.V. Transgranichnoe bankrotstvo: rossiiskie pravovye realii i perspektivy // Zakon. 2014. № 6. S. 62-73;

3. Mokhova E.V. Osparivanie v rossiiskom sude sdelok bankrotyashchegosya za rubezhom dolzhnika. Kommentarii k Postanovleniyu Prezidiuma VAS RF ot 12.11.2013 № 10508/13 po delu banka SNORAS // Vestnik VAS RF. 2014. № 5. S. 48 - 66;

4. Mokhova E.V. Potrebnosti i perspektivy regulirovaniya transgranichnoi nesostoyatel'nosti v Rossiiskoi Federatsii // Rossiiskoe pravosudie. 2013. № 4;

5. Mokhova E.V. Tsentr osnovnykh interesov dolzhnika pri transgranichnoi nesostoyatel'nosti: perspektivy vvedeniya v Rossii novykh pravovykh konstruktsii // Zakon. 2012. № 10. S. 111 - 127;

6. Mokhova E.V. Doktrina modifitsirovannogo universalizma kak osnova regulirovaniya transgranichnoi nesostoyatel'nosti: razgranichenie kompetentsii sudov razlichnykh gosudarstv. M., 2009. S. 10-54;

7. Anufrieva L.P. Mezhdunarodnoe chastnoe pravo: V 3 t. T. 3: Transgranichnye bankrotstva. Mezhdunarodnyi kommercheskii arbitrazh. Mezhdunarodnyi grazhdanskii protsess. M., 2001. S. 8;

8. Erpyleva N.Yu. Mezhdunarodnoe chastnoe pravo: Uchebnik. M., 2004. S. 126;

9. Letin A.V. Transgranichnaya nesostoyatel'nost' kak ob"ekt nauki MChP // Gosudarstvo i pravo. 2003. № 8. S. $80-81$;

10. Trushnikov S.S. Vozbuzhdenie proizvodstva po delam o nesostoyatel'nosti v Rossii i Germanii. SPb., 2006. S. 155 ;

11. Sobina L.Yu. Priznanie inostrannykh bankrotstv v mezhdunarodnom chastnom prave. M.: Statut, 2012. S 195-205;

12. M'yuchurelli F. M. Svoboda perevoploshcheniya v sfere korporativnogo prava SShA i ES // nauchnyi doklad v N’yu-Iorkskom universitete prava i ekonomiki № 11-07.2011, Mart 11. URL-adres: http://ssrn.com/abstract $=1783607$ (data obrashcheniya: 24.11.2015);

13. Gerner-Boiole S., Shilig M. Tainy svobody uchrezhdeniya posle Cartesio // Mezhdunarodnoe i Sravnitel'noe pravo. 2010. Vyp. 59. № 2. URL: http://ssrn.com/abstract=1340964 (data obrashcheniya: 24.11.2015);

14. Vimersh E. Peredacha kompanii Seat v Evropeiskom korporativnom prave // ECGI-Law Working Paper № 08/2003. URL-adres: http://ssrn.com/abstract=384802 (data obrashcheniya: 24.11.2015);

15. M'yuchurelli F. M. O neizbezhnom sokhraneniem poiska udobnogo suda v Evropeiskom zakonodatel'stve o nesostoyatel'nosti. S. 6 - 7. URL: http://ssrn.com/abstract=2375654 (data obrashcheniya: 24.11.2015); 
DOI: $10.7256 / 2226-6305.2016 .2 .17082$

При цитировании этой статьи сноска на doi обязательна

Международное право и международные организации•2•2016 International Law and International Organizations

16. Arauzho A. P., i soavt., Opyt primeneniya Brazil'skogo zakona o bankrotstve, Dzh. korp. Finansy (2012), doi:10.1016/j.jcorpfin.2012.03.001. URL: http://static1.squarespace.com/static/553c6154e4b0ed6ca351a744/t/ 55561788e4b0342593f78d66/1431705480639/pesquisa+03.pdf (data obrashcheniya 24.11.2015);

17. Laskina S. O. Zashchita zakonnykh finansovykh interesov gosudarstva pri bankrotstve yuridicheskikh lits: avtoref. dis. ... kand. yurid. nauk. M., 2010. S. 22;

18. Laskina S. O. Nalogovye obyazatel'stva v dele o bankrotstve // Khozyaistvo i pravo. 2009 № 12. - S. 63 - 78;

19. Uolters A., Smit A. «Bankrotnyi turizm» po postanovleniyu ES o protsedurakh nesostoyatel'nosti: vzglyad iz Anglii i Uel'sa // Kommentarii k mezhdunarodnoi nesostoyatel'nosti. 2009. Vyp. 19. № 3. P. 181-208; URL: https://www.ntu.ac.uk/PSS/Nottingham\%20Law\%20School/Publications/99914.pdf. (data obrashcheniya 24.11.2015). 